\title{
Glycolytic Inhibition: Effects on Diastolic Relaxation and Intracellular Calcium Handling in Hypertrophied Rat Ventricular Myocytes
}

Yutaka Kagaya, ${ }^{\star}$ Ellen O. Weinberg, ${ }^{*}$ Nobuhiko Ito, ${ }^{*}$ Takatoshi Mochizuki, ${ }^{*}$ William H. Barry, ${ }^{\star}$ and Beverty H. Lorell”

*The Charles A. Dana Research Institute and the Harvard-Thorndike Laboratory of Beth Israel Hospital and the Department of Medicine, Cardiovascular Division, Beth Israel Hospital, and Harvard Medical School, Boston, Massachusetts 02215; and ${ }^{\ddagger}$ Division of Cardiology, Department of Medicine, University of Utah School of Medicine, Salt Lake City, Utah 84132

\begin{abstract}
We tested the hypothesis that glycolytic inhibition by 2 deoxyglucose causes greater impairment of diastolic relaxation and intracellular calcium handling in well-oxygenated hypertrophied adult rat myocytes compared with control myocytes. We simultaneously measured cell motion and intracellular free calcium concentration $\left(\left[\mathrm{Ca}^{2+}\right]_{1}\right)$ with indo1 in isolated paced myocytes from aortic-banded rats and sham-operated rats. There was no difference in either the end-diastolic or peak-systolic $\left[\mathrm{Ca}^{2+}\right]_{1}$ between control and hypertrophied myocytes ( $97 \pm 18$ vs. $105 \pm 15 \mathrm{nM}, 467 \pm 92$ vs. $556 \pm 67 \mathrm{nM}$, respectively). Myocytes were first superfused with oxygenated Hepes-buffered solution containing $1.2 \mathrm{mM}$ $\mathrm{CaCl}_{2}, 5.6 \mathrm{mM}$ glucose, and $5 \mathrm{mM}$ acetate, and paced at 3 $\mathrm{Hz}$ at $36^{\circ} \mathrm{C}$. Exposure to $20 \mathrm{mM}$ 2-deoxyglucose as substitution of glucose for 15 min caused an upward shift of enddiastolic cell position in both control $(n=5)$ and hypertrophied myocytes $(n=10)(P<0.001$ vs. baseline $)$, indicating an impaired extent of relaxation. Hypertrophied myocytes, however, showed a greater upward shift in end-diastolic cell position and slowing of relaxation compared with control myocytes $(\Delta 144 \pm 28$ vs. $55 \pm 15 \%$ of baseline diastolic position, $P<0.02)$. Exposure to 2-deoxyglucose increased enddiastolic $\left[\mathrm{Ca}^{2+}\right]_{1}$ in both groups $(P<0.001$ vs. baseline $)$, but there was no difference between hypertrophied and control myocytes ( $218 \pm 38 \mathrm{vs.} 183 \pm 29 \mathrm{nM}$, respectively ). The effects of 2-deoxyglucose were corroborated in isolated oxygenated perfused hearts in which glycolytic inhibition which caused severe elevation of isovolumic diastolic pressure and prolongation of relaxation in the hypertrophied hearts compared with controls. In summary, the inhibition of the glycolytic pathway impairs diastolic relaxation to a greater extent in hypertrophied myocytes than in control myocytes even in well-oxygenated conditions. The severe impairment of diastolic relaxation induced by 2-deoxyglucose in hypertrophied myocytes compared with control myocytes cannot be explained by greater diastolic $\mathrm{Ca}^{2+}$ overload, which implicates an increase in myofilament $\mathrm{Ca}^{2+}$-responsiveness as a possible mechanism. (J. Clin. Invest. 1995. 95:2766-2776.)
\end{abstract}

Address correspondence to Beverly H. Lorell, M.D., Cardiovascular Division, Beth Israel Hospital, 330 Brookline Ave., Boston, MA 02215. Phone: 617-667-2686; FAX: 617-667-4833.

Received for publication 18 July 1994 and in revised form 21 February 1995.

J. Clin. Invest.

(c) The American Society for Clinical Investigation, Inc.

0021-9738/95/06/2766/11 $\$ 2.00$

Volume 95, June 1995, 2766-2776
Key words: glycolysis $\bullet$ 2-deoxyglucose $\bullet$ hypertrophy $\bullet$ myocytes $\cdot$ diastolic relaxation $\cdot$ calcium

\section{Introduction}

Cardiac hypertrophy is characterized by multiple changes in gene programming which modify the integration of pathways utilized for energy synthesis and maintenance of intracellular calcium homeostasis $(1-3)$. Previous studies have shown that hypertrophied hearts have an enhanced susceptibility to develop impaired diastolic relaxation during hypoxia and ischemia (46) which can be modified by stimulation of glycolytic flux during energy depletion (7). These studies suggest that hypertrophied hearts may be more dependent on glycolytic flux to maintain normal relaxation even under well-oxygenated conditions in comparison with normal hearts (8). There is evidence that glycolytic flux is closely linked with diastolic relaxation and transsarcolemmal ion flux, implicating a role in the restoration of resting cytosolic $\mathrm{Ca}^{2+}$ levels $(9,10)$. Ikenouchi et al. (11) demonstrated that glycolytic inhibition by 2-deoxyglucose (2DG) ${ }^{1}$ causes impairment of myocyte relaxation in association with an increase in diastolic intracellular $\mathrm{Ca}^{2+}$ in normal isolated cultured embryonic chick myocytes and paced adult rabbit ventricular myocytes under oxygenated conditions.

The goal of this study was to test the hypothesis that glycolytic inhibition by 2DG causes greater impairment of diastolic relaxation and more severe elevation of diastolic intracellular $\mathrm{Ca}^{2+}$ in isolated, well-oxygenated hypertrophied myocytes in comparison with normal myocytes. We simultaneously measured intracellular calcium concentration $\left(\left[\mathrm{Ca}^{2+}\right]_{i}\right)$ using the fluorescence $\mathrm{Ca}^{2+}$ indicator indo-1 AM in collagenase-dissociated, paced myocytes isolated from aortic-banded and shamoperated rats. Myocytes were superfused with $20 \mathrm{mM}$ 2DG for $15 \mathrm{~min}$ in the presence of acetate as substrate for mitochondrial oxidative phosphorylation. The results of the present study indicate that glycolytic inhibition by $2 \mathrm{DG}$ elicits greater impairment of diastolic relaxation in hypertrophied myocytes than control myocytes. Partial metabolic inhibition with 2DG caused an increase in diastolic $\left[\mathrm{Ca}^{2+}\right]_{i}$ in the myocytes despite the presence of acetate as substrate for mitochondrial oxidative phosphorylation. However, the increase in diastolic $\left[\mathrm{Ca}^{2+}\right]_{i}$ was similar in hypertrophied and normal myocytes, implicating an increase in myofilament $\left[\mathrm{Ca}^{2+}\right]_{\mathrm{i}}$ responsiveness as the mechanism of the severe deterioration in diastolic relaxation in hypertrophied myocytes.

\section{Methods}

Preparation of aortic-banded rats. Weanling male Wistar rats (Charles River Breeding Laboratories, Wilmington, DE) were banded at the age

1. Abbreviations used in this paper: 2DG, 2-deoxyglucose; BDM, 2,3butanedione monoxime. 
of 3-4 wk (body weight, $75-100 \mathrm{~g}$ ) by placing a stainless steel clip of $0.6 \mathrm{~mm}$ internal diameter on the ascending aorta via a thoracic incision $(6,13,14)$. Age-matched control rats underwent a sham-operation. The rats were fed normal rat chow and water ad libitum, and were used 8-9 wk after the banding. Previous studies in our laboratory have shown that at this stage after aortic banding, this model of pressure-overload hypertrophy is characterized by a $50-60 \%$ increase in left ventricular weight relative to sham-operated controls and the absence of chamber dilatation $(6,12,13)$.

Dissociation of left ventricular myocytes. Left ventricular myocyte isolation was performed by a modification of the methods of Capogrossi et al. (14) and Haddad et al. (15). Rats were anesthetized with an intraperitoneal injection of pentobarbital sodium $(65 \mathrm{mg} / \mathrm{kg}$ body weight). The heart was rapidly excised and attached to an aortic cannula. Continuous retrograde coronary perfusion was initiated at a perfusion pressure of $70 \mathrm{~cm} \mathrm{H}_{2} \mathrm{O}$ for control hearts and $100 \mathrm{~cm} \mathrm{H}_{2} \mathrm{O}$ for hypertrophied hearts. The heart was first perfused with nominally $\mathrm{Ca}^{2+}$-free modified Krebs-Henseleit buffer of the following composition: $123 \mathrm{mM}$ $\mathrm{NaCl}, 5.4 \mathrm{mM} \mathrm{KCl}, 1.2 \mathrm{mM} \mathrm{MgSO}, 1.2 \mathrm{mM} \mathrm{NaH}_{2} \mathrm{PO}_{4}, 20 \mathrm{mM}$ $\mathrm{NaHCO}_{3}$, and $11 \mathrm{mM}$ glucose. This medium was not recirculated and was continuously gassed with $95 \% \mathrm{O}_{2}$ and $5 \% \mathrm{CO}_{2}$ (pH of 7.4 and temperature of $36-37^{\circ} \mathrm{C}$ ). After $3 \mathrm{~min}$ of the initial perfusion, the heart was perfused with recirculating Krebs-Henseleit buffer supplemented with $0.6 \mathrm{mg} / \mathrm{ml}$ collagenase (Class II, Worthington Biochemical Corp., Freehold, NJ), $0.04 \mathrm{mg} / \mathrm{ml}$ protease (Type XIV; Sigma Immunochemicals, St. Louis, MO) for 20-40 min. The heart was then detached from the cannula. The left ventricle was cut into small pieces, and the dispersion of the myocytes was performed by gentle agitation of ventricular tissue through a serologic pipette in Krebs-Henseleit buffer containing $100 \mu \mathrm{M} \mathrm{CaCl}_{2}$ and $1 \mathrm{mg} / \mathrm{ml}$ bovine serum albumin. The resulting suspension was then gently forced through a $450-\mu \mathrm{m}$ nylon screen filtration cloth into a 50-ml plastic tube, and rinsed twice. The myocytes were then resuspended in Hepes-buffered solution of the following composition: $137 \mathrm{mM} \mathrm{NaCl}, 5.4 \mathrm{mM} \mathrm{KCl}, 1.2 \mathrm{mM} \mathrm{MgSO}_{4}, 1.2$ $\mathrm{mM} \mathrm{NaH} \mathrm{PO}_{4}, 20 \mathrm{mM}$ Hepes (free acid), $1.2 \mathrm{mM} \mathrm{CaCl}, 20 \mathrm{mM}$ glucose, and $5 \%$ fetal bovine serum. The myocytes were stored at $36^{\circ} \mathrm{C}$ for $1 \mathrm{~h}$.

Simultaneous measurement of $\left[\mathrm{Ca}^{2+}\right]_{i}$ and cell motion. $\left[\mathrm{Ca}^{2+}\right]_{\mathrm{i}}$ was measured with $\mathrm{Ca}^{2+}$-sensitive fluorescence indicator indo-1 AM (16) (Molecular Probes, Inc., Eugene, OR) prepared by modification of the method of duBell et al. (17) and Ikenouchi et al. (11). First, $10 \mathrm{ml}$ of fetal bovine serum was mixed with $234 \mu \mathrm{l}$ of $25 \%$ Pluronic F 127 (BASF Wyandotte Corp., Parsippany, NJ) dissolved in dimethyl-sulfoxide. Then $1 \mathrm{ml}$ of $1 \mathrm{mM}$ indo-1 AM in dimethyl-sulfoxide was added to $9 \mathrm{ml}$ of fetal bovine serum-Pluronic F 127 mixture, sonicated, and aliquoted into $400-\mu \mathrm{l}$ samples, which were stored at $-20^{\circ} \mathrm{C}$. Myocytes were attached on coverslips with cell adhesive (Cell-Tak; Collaborative Research, Inc., Waltham, MA), and loaded with $5 \mu \mathrm{M}$ indo-1 AM in Hepes-buffered solution at room temperature for $30 \mathrm{~min}$. The coverslip was rinsed with indo-1 AM-free buffer solution, and placed in a flowthrough heated $\left(36^{\circ} \mathrm{C}\right)$ cell superfusion chamber on the stage of an inverted microscope (Nikon, Tokyo, Japan). The instrumentation for fluorescence measurement has been described in detail elsewhere (11, 18, 19). The excitation source was a high-pressure $\mathrm{Hg}$-arc lamp which provides an intense emission peak at $360 \mathrm{NM}$. Further selection of this excitation was made with narrow band width interference filters. The excitation beam was chopped at $360 \mathrm{~Hz}$ to reduce bleaching and the myocyte was illuminated via epifluorescent optics using Fluor $\times 40$ objective lens (Nikon). The fluorescence light was collected by the objective lens and transmitted to a custom-modified spectrofluorimeter (FM-1000; Rincon Scientific Instruments, Santa Barbara, CA) for simultaneous measurement of both 400 and $500 \mathrm{NM}$ wavelengths using two separate photomultiplier tubes. The spectrofluorimeter provided analog signals representing the fluorescence intensity at both wavelengths and the ratio of emitted fluorescence $(400 / 500 \mathrm{NM})$. The subtraction of background autofluorescence was done by offsetting the photomultiplier tube outputs during the measurement of fluorescence from an unloaded myocyte at the beginning of each experiment. An adjustable iris was used to restrict the optical image to only one myocyte of interest in each experiment to minimize background fluorescence from other myocytes. The image of the beating myocyte was obtained by illumination via the 50-w standard microscope light source passed through a 645 nm band-pass filter. This wavelength was long enough not to interfere with the fluorescence detection at 400 and $500 \mathrm{NM}$. The motion of the myocyte was monitored using a solid state camera (GP-CD60; Panasonic, Secaucus, NJ) and a custom-modified video detector system (20) (Crescent Electronics, Sandy, UT). The analogue output of the cell motion signal was monitored and recorded continuously with the analog signal of the $\left[\mathrm{Ca}^{2+}\right]_{i}$ sensitive fluorescence ratio (F400/500 NM). Two platinum electrodes placed in the bathing fluid were connected to a stimulator (SD9G, Grass Instruments, Quincy, MA), and used to stimulate the myocyte at 0.5 or $3 \mathrm{~Hz}$ with 3 -ms pulses.

Total numbers of hearts used for the isolation of myocytes in the present experiments were 12 from sham-operated rats, and 14 from aortic-banded rats. The yield of viable myocytes, which were defined as the percentage of rod-shaped myocytes with clear striations and exclusion of trypan blue, were $60-70 \%$ in control myocytes, and $50-60 \%$ in hypertrophied myocytes. To prevent bias when we selected a myocyte to be analyzed among myocytes in a microscopic field, we chose a rodshaped myocyte with very clear striation, without any spontaneous cell motion oscillations, and with visually moderate cell motion amplitude of contraction $(3.0-3.5 \mu \mathrm{m})$ at a pacing rate of $0.5 \mathrm{~Hz}$. This selection is against the potential bias to select excessively vigorous myocytes rather than depressed myocytes. One to three experiments were performed in sequence from separate coverslips of myocytes isolated from one heart.

Intracellular calcium calibration. To determine the absolute values of peak-systolic and end-diastolic $\left[\mathrm{Ca}^{2+}\right]_{i}$ under baseline conditions in hypertrophied and control myocytes, we performed calibration studies by a modification of the methods of Cheung et al. (21), and Borzak et al (22). For quantitative calibration of myocyte $\left[\mathrm{Ca}^{2+}\right]_{i}$, the low level of background cell autofluorescence and photomultiplier tube dark current was subtracted from the fluorescence emission of indo-1-loaded cells. To accomplish this, an unloaded coverslip of dissociated myocytes was placed into the perfusion chamber and the photomultiplier tube outputs offset to zero, then coverslips of indo-1-loaded myocytes from the same dissociated cells were placed in the chamber. The myocytes loaded with indo-1 AM were superfused with Hepes-buffered normal Tyrode solution ( $\mathrm{pH}, 7.40$ ) containing $1.2 \mathrm{mM} \mathrm{CaCl}_{2}$, and single cell $\left[\mathrm{Ca}^{2+}\right]_{\mathrm{i}}$ transients were detected at the pacing rate of $3 \mathrm{~Hz}$. Immediately after the $\left[\mathrm{Ca}^{2+}\right]_{\mathrm{i}}$ transients and the fluorescence intensities at 400 and $500 \mathrm{NM}$ were recorded, the cells were superfused with the same buffer supplemented with $40 \mathrm{mM}$ 2,3-butanedione monoxime (BDM) and the nonfluorescent $\mathrm{Ca}^{2+}$ ionophore $10 \mu \mathrm{M}$ ionomycin to measure the maximum value of ratio $\left(R_{\max }\right)$ in the presence of $1.2 \mathrm{mM} \mathrm{CaCl}{ }_{2} . B D M$ completely inhibits $\mathrm{Ca}^{2+}$-induced force development, preventing an alteration of fluorescence due to $\mathrm{Ca}^{2+}$-induced hypercontracture of the myocytes (21). The cells then were superfused with zero $\mathrm{Ca}^{2+}$ buffer made with $10 \mathrm{mM}$ EGTA and nominal zero $\mathrm{Ca}^{2+}$ to evaluate minimum value of ratio $\left(R_{\min }\right) \cdot\left[\mathrm{Ca}^{2+}\right]_{i}$ was estimated by the equation of Grynkiewicz et al. (16):

$\left[\mathrm{Ca}^{2+}\right]_{\mathrm{i}}=K_{\mathrm{d}} \times \beta\left(R-R_{\min }\right) /\left(R_{\max }-R\right)$

where $K_{\mathrm{d}}$ is the dissociation constant for indo-1 and taken to be 250 NM (16), $\beta$ is the ratio of fluorescence intensity in zero and saturating $\mathrm{Ca}^{2+}$, and $\mathrm{R}$ is the ratio of two fluorescence intensities measured at 400 and 500 NM. Since BDM has been known to slightly decrease fluorescence intensity (22), correction factors for $R_{\max }, R_{\min }$, and $\beta$ were obtained from a cuvette experiment as described below. Fluorescence intensities at $\mathbf{4 0 0}$ and $500 \mathrm{NM}$ were measured in quartz cuvettes with four different solutions: ( $a$ ) Hepes ( $4 \mathrm{mM}$ ) buffered solution containing $140 \mathrm{mM} \mathrm{KCl}, 5 \mu \mathrm{M}$ indo-1-free acid (Calbiochem Norabiochem, La Jolla, CA), and $100 \mu \mathrm{M} \mathrm{CaCl}_{2} ;($ b $)$ solution A with $40 \mathrm{mM} \mathrm{BDM;} \mathrm{(c)}$ Hepes ( $4 \mathrm{mM}$ ) buffered solution containing $140 \mathrm{mM} \mathrm{KCl}, 5 \mu \mathrm{M}$ indo1 -free acid, and $100 \mu \mathrm{M}$ EGTA; and (d) solution $\mathrm{C}$ with $40 \mathrm{mM}$ BDM. 
The $\mathrm{pH}$ of these solutions was adjusted to 7.20. Correction factors (C) accounting for the effects of BDM were calculated as follows:

$$
\begin{aligned}
& \mathrm{C}_{1}=R_{\max , \operatorname{BDM}(-)} / R_{\max , \operatorname{BDM}(+)} \\
& \mathrm{C}_{2}=R_{\min ,(\operatorname{BDM})(-)} / R_{\min , \operatorname{BDM}(+)} \\
& \mathrm{C}_{3}=\beta_{\mathrm{BDM}(-)} / \beta_{\mathrm{BDM}(+)}
\end{aligned}
$$

where $R_{\max , \mathrm{BDM}(-)}, R_{\max , \mathrm{BDM}(+)}, R_{\min , \mathrm{BDM}(-)}$, and $R_{\min , \mathrm{BDM}(+)}$ are the ratios of fluorescence intensity at 400-500 NM obtained from solutions $\mathrm{A}, \mathrm{B}, \mathrm{C}$, and $\mathrm{D}$, respectively. $\beta_{\mathrm{BDM}(-)}$, and $\beta_{\mathrm{BDM}(+)}$ are defined as the ratios of fluorescence at $500 \mathrm{NM}$ with solution $C$ to $A$, and solution $D$ to $\mathrm{B}$, respectively. Thus, $\left[\mathrm{Ca}^{2+}\right]_{\mathrm{i}}$ was calculated by modification of equation of Grynkiewicz et al. (16):

$\left[\mathrm{Ca}^{2+}\right]_{\mathrm{i}}=K_{\mathrm{d}} \times \beta^{\prime}\left(R-R_{\text {min }}^{\prime}\right) /\left(R_{\text {max }}^{\prime}-R\right)$

where $K_{\mathrm{d}}$ is the dissociation constant for indo-1 and taken to be 250 $\mathrm{NM}$, and $\mathrm{R}_{\max }^{\prime}, \mathrm{R}_{\min }^{\prime}$, and $\beta^{\prime}$ are calculated using correction factors as follows:

$$
\begin{aligned}
R_{\text {max }}^{\prime} & =\mathrm{C}_{1} \times R_{\text {max }} \\
R_{\text {min }}^{\prime} & =\mathrm{C}_{2} \times R_{\text {min }} \\
\beta^{\prime} & =\mathrm{C}_{3} \times \beta
\end{aligned}
$$

where $R_{\max }^{\prime}$ is the corrected maximum value of the ratio, $R_{\min }^{\prime}$ is the corrected minimum value of the ratio, and $\beta^{\prime}$ is the corrected ratio of $500 \mathrm{NM}$ fluorescence intensity in zero and saturating $\mathrm{Ca}^{2+}$ recorded from a myocyte superfused with the buffer containing $40 \mathrm{mM}$ BDM. In the protocols described below, $\left[\mathrm{Ca}^{2+}\right]_{i}$ was then calculated by converting the $\mathrm{F} 400 / \mathrm{F} 500$ ratio values to $\left[\mathrm{Ca}^{2+}\right]_{\mathrm{i}}$ using the regression line obtained from the calibration study.

Experimental protocol. Hypertrophied $(n=10)$ and control $(n$ $=5$ ) myocytes were superfused with oxygenated Hepes-buffered normal Tyrode solution of the following composition: $137 \mathrm{mM} \mathrm{NaCl}, 3.7 \mathrm{mM}$ $\mathrm{KCl}, 0.5 \mathrm{mM} \mathrm{MgCl}$, $4 \mathrm{mM}$ Hepes (free acid), $1.2 \mathrm{mM} \mathrm{CaCl}$, 5.6 $\mathrm{mM}$ glucose, $5.0 \mathrm{mM}$ acetate, and $0.5 \mathrm{mM}$ probenecid with a final $\mathrm{pH}$ of 7.40. Probenecid, a blocker of organic anion transport, was added as it has been shown to inhibit secretion of both indo-1-and fura-2-free acids from loaded cells $(23,24)$. The temperature of the myocytes was maintained at $36-37^{\circ} \mathrm{C}$. The myocytes were first paced at $0.5 \mathrm{~Hz}$, then the pacing rate was gradually increased to $3 \mathrm{~Hz}$. After recording baseline data, the cells were superfused with oxygenated Hepes-buffered solution containing $20 \mathrm{mM} 2 \mathrm{DG}$ as substitution of glucose in the presence of 5 $\mathrm{mM}$ acetate for $15 \mathrm{~min}$. The analogue cell motion signals and the F400:500 NM analog signals were recorded simultaneously. The F400/ 500 values were converted to $\left[\mathrm{Ca}^{2+}\right]_{\mathrm{i}}$ using the procedure described in the previous section.

In a separate experiment, we studied the effects of iodoacetate (25), another inhibitor of glycolysis, on cell motion and intracellular calcium handling in additional control $(n=3)$ and hypertrophied $(n=5)$ myocytes. First, myocytes were superfused with the same Hepes-buffered solution used for baseline superfusion in the 2DG protocol, then with the same solution containing $0.15 \mathrm{mM}$ iodoacetate as substitution for glucose. The temperature, $\mathrm{pH}$ and the pacing rate were the same as those in the 2DG protocol.

Effects of BDM on increased diastolic cell position induced by $2 D G$ in hypertrophied myocytes. To investigate whether increased diastolic cell position in hypertrophied myocytes exposed to 2DG is due to irreversible $\mathrm{Ca}^{2+}$-independent rigor or $\mathrm{Ca}^{2+}$-dependent crossbridge cycling, a separate experiment was performed in hypertrophied myocytes $(n$ $=3$ ) using BDM, which uncouples contractile activity from $\mathrm{Ca}^{2+}$ transients $(26,27)$. Hypertrophied myocytes were first superfused with the same solution used for baseline superfusion in the 2DG protocol. The superfusate was then switched to the solution with $20 \mathrm{mM} 2 \mathrm{DG}$ as substitution of glucose. When diastolic cell position shifted upward by at least 100 percent of baseline cell position (9-15 min after the exposure), the myocytes were abruptly superfused with the same $20 \mathrm{mM}$ 2DG solution supplemented with $20 \mathrm{mM}$ BDM.
Stability study. The stability of both cell motion and $\left[\mathrm{Ca}^{2+}\right]_{\mathrm{i}}$ were assessed for a period of $15 \mathrm{~min}$ in both hypertrophied $(n=3)$ and control $(n=4)$ myocytes. Myocytes were superfused with oxygenated Hepes-buffered solution ( $\mathrm{pH} 7.40$ ) containing: $137 \mathrm{mM} \mathrm{NaCl}, 3.7 \mathrm{mM}$ $\mathrm{KCl}, 0.5 \mathrm{mM} \mathrm{MgCl}$, $4 \mathrm{mM}$ Hepes (free acid), $1.2 \mathrm{mM} \mathrm{CaCl}, 5.6$ $\mathrm{mM}$ glucose, and $5 \mathrm{mM}$ acetate, and probenecid 0.5 . Cells were paced at $3 \mathrm{~Hz}$ at $36-37^{\circ} \mathrm{C}$.

Compartmentation study. To estimate compartmentation of indo-1 in intracellular organelles, myocytes loaded with indo-1 AM from shamoperated or aortic-banded rats ( $n=3$ in each group) were chemically skinned by superfusion with Hepes-buffered ( $4 \mathrm{mM}$ ) normal Tyrode solution ( $\mathrm{pH} 7.05$ ) containing $25 \mu \mathrm{M}$ digitonin, $10 \mathrm{mM} \mathrm{CaCl}_{2}$ and 30 mM BDM (19). As previously described, this concentration of digitonin is sufficient to permeabilize the membrane to permit loss of free intracellular $\mathrm{Ca}^{2+}$ bound to indo-1 without disrupting organelles (18). Fluorescence intensities from the myocyte were continuously recorded at both 400 and $500 \mathrm{NM}$.

Isolated heart studies. To assure that the results obtained in isolated myocytes were representative of the behavior of the intact heart, the 2DG perfusion protocol described above in the isolated myocytes were repeated in isolated buffer-perfused hearts from additional aortic-banded rats 8-9 wk after banding $(n=7)$ and age-matched sham-operated controls $(n=7)$. The isovolumic buffer-perfused heart preparation has been described in detail previously $(11,12,13)$. Left ventricular isovolumic balloon volume was adjusted to achieve a left ventricular end-diastolic pressure of $10 \mathrm{mmHg}$ in both groups; at this level of diastolic pressure, balloon volume was comparable in the hypertrophy and control groups $(0.19 \pm 0.01$ vs. $0.21 \pm 0.02 \mathrm{ml}, \mathrm{NS})$. Coronary flow rate was adjusted to achieve a similar flow rate/per gram in both groups ( $13.0 \pm 0.5$ vs. $12.8 \pm 0.4 \mathrm{ml} / \mathrm{min}$ per gram, NS). The hearts were paced at $3-4 \mathrm{~Hz}$ and temperature was maintained at $36^{\circ} \mathrm{C}$. After a $30-\mathrm{min}$ stabilization period with the baseline perfusate, left ventricular pressure and coronary perfusion pressure were measured. All hearts were then perfused with the well-oxygenated 2DG solution for eight minutes and hemodynamic measurements were repeated. Pilot studies showed that perfusion with the 2DG solution for $15 \mathrm{~min}$, as was done in the isolated myocytes, was not feasible due to development of arrhythmias with irreversible contracture in the hypertrophied hearts.

Analysis of high energy phosphate contents. Myocardial ATP and phosphocreatine contents were determined in the perfused hearts at 8 min of 2DG infusion. At the end of the experiment, the heart was quickly trimmed of atria and right ventricular free wall, frozen with liquid nitrogen-cooled clamps, and the LV was rapidly weighed and then heated $\left(37^{\circ} \mathrm{C}\right)$ in an oven for $48 \mathrm{~h}$ to determine the frozen/dry weight ratio. The remainder of the sample was mixed with $0.6 \mathrm{~N}$ perchloric acid, homogenized, centrifuged, and neutralized with $5 \mathrm{~mol} / \mathrm{l}$ potassium carbonate. The aliquot of neutralized homogenate was placed in preweighed reagent vials and analyzed for ATP by methods of Adams (28). Phosphocreatinine was measured by the methods of Altschuld (29) by adding an excess of creatine kinase to the ATP reaction mixture after ATP assay had reached completion. Additional control hearts ( $n$ $=5)$ and hypertrophied hearts $(n=5)$ were also frozen for determination of baseline myocardial high-energy phosphate values after a 30min stabilization period of perfusion with the control solution containing glucose. Measurements are expressed as $\mu \mathrm{mol} / \mathrm{g}$ left ventricular dry weight.

Statistical analysis. Two-way analysis of variance (ANOVA) with repeated measures was used for the comparisons between the control versus hypertrophied myocytes, or control versus hypertrophied perfused hearts, of values measured over time during 2DG and iodoacetate superfusions. Unpaired Student's $t$ test was used for comparisons of the values between the groups at baseline. A $P$ value of $<0.05$ was considered significant. Results are expressed as mean \pm SEM.

\section{Results}

Both left ventricular weight and left ventricular weight/body weight ratio were significantly increased in left ventricles from 
Table I. Baseline Characteristics of Myocyte Function and Intracellular $\mathrm{Ca}^{2+}$

\begin{tabular}{lcc}
\hline & $\begin{array}{c}\text { Control } \\
n=8\end{array}$ & $\begin{array}{c}\text { Hypertrophy } \\
n=15\end{array}$ \\
\hline Myocyte length $(\mu \mathrm{m})$ & $150 \pm 6$ & $167 \pm 5^{*}$ \\
Amplitude of cell shortening $(\mu \mathrm{m})$ & $3.2 \pm 0.5$ & $3.2 \pm 0.3$ \\
Fractional myocyte shortening $(\%)$ & $2.24 \pm 0.45$ & $1.94 \pm 0.17$ \\
Time to peak shortening $(\mathrm{ms})$ & $52 \pm 4$ & $72 \pm 4^{\ddagger}$ \\
Time to $50 \%$ relengthening $(\mathrm{ms})$ & $36 \pm 3$ & $48 \pm 4$ \\
Peak positive first derivative of cell & & \\
$\quad$ motion $(\mu \mathrm{m} / \mathrm{s})$ & $123 \pm 19$ & $86 \pm 7^{*}$ \\
Peak negative first derivative of cell & & \\
$\quad$ motion $(\mu \mathrm{m} / \mathrm{s})$ & $-88 \pm 13$ & $-63 \pm 8$ \\
Time to peak $\left[\mathrm{Ca}^{2+}\right]_{\mathrm{i}}(\mathrm{ms})$ & $48 \pm 2$ & $53 \pm 3$ \\
Time to $50 \%$ decline in $\left[\mathrm{Ca}^{2+}\right]_{\mathrm{i}}$ from & & \\
$\quad$ peak $(\mathrm{ms})$ & $78 \pm 5$ & $80 \pm 4$ \\
End-diastolic $\left[\mathrm{Ca}^{2+}\right]_{\mathrm{i}}(\mathrm{nM})$ & $97 \pm 18$ & $105 \pm 15$ \\
Peak-systolic $\left[\mathrm{Ca}^{2+}\right]_{\mathrm{i}}(\mathrm{nM})$ & $467 \pm 92$ & $556 \pm 67$
\end{tabular}

Mean \pm SEM. ${ }^{*} P<0.05$ versus control myocytes. ${ }^{\ddagger} P<0.01$ versus control myocytes. All data were obtained under baseline perfusion conditions of $36^{\circ} \mathrm{C}$, perfusate $\left[\mathrm{Ca}^{2+}\right] 1.2 \mathrm{mM}$, and paced rate of $3 \mathrm{~Hz}$.

aortic-banded rats compared with those from sham-operated rats $(2,501 \pm 100$ vs. $1,943 \pm 72 \mathrm{mg}, P<0.001$ and $5.06 \pm 0.11$ vs. $3.84 \pm 0.10 \mathrm{mg} / \mathrm{g}, P<0.001$, respectively). Table I shows baseline function of left ventricular control myocytes $(n=8)$ from sham-operated rats and hypertrophied myocytes $(n=15)$ from the aortic-banded rats used in both the 2DG and the iodoacetate protocols. Myocytes were superfused with oxygenated normal Tyrode solution $(\mathrm{pH} 7.40)$ containing $1.2 \mathrm{mM}$ $\mathrm{CaCl}_{2}, 5.6 \mathrm{mM}$ glucose, and $5 \mathrm{mM}$ acetate at $36-37^{\circ} \mathrm{C}$, and were paced at $3 \mathrm{~Hz}$. There was a significant increase in myocyte cell length in hypertrophied myocytes compared with controls. While amplitude of cell motion and percent fractional shortening was not statistically different between the two groups, both time to peak shortening and the peak positive first derivative of cell motion were significantly impaired in hypertrophied myocytes compared with control myocytes (Table I). Both time to 50 percent relengthening and peak negative first derivative of cell motion were similar in the control and hypertrophied myocytes.

The stability of cell motion and $\left[\mathrm{Ca}^{2+}\right]_{\mathrm{i}}$ signal for a period of $15 \mathrm{~min}$ were evaluated in both hypertrophied and control myocytes ( $n=3$ in each group). Both cell motion and the $\left[\mathrm{Ca}^{2+}\right]_{\mathrm{i}}$ transient signals were stable for the 15 -min time interval utilized during the 2DG protocol in both hypertrophied and normal myocytes. As indo-1 can buffer cytosolic $\mathrm{Ca}^{2+}$, it is possible that any buffering effect of indo-1 might be different between control and hypertrophied myocytes. For this reason, we studied the effects of loading with indo-1 AM on both amplitude of cell motion and time to peak shortening in additional control and hypertrophied myocytes with and without loading ( $n=8-9$ in each group). Those values were not statistically significantly different in the presence or absence of indo1 AM loading in either control and hypertrophied myocytes. The amplitude of cell motion, however, tended to be decreased in both control and hypertrophied myocytes loaded with indo1 AM compared with the absence of loading $(-13.6 \%$ in control myocytes and $-11.8 \%$ in hypertrophied myocytes), suggesting that any $\mathrm{Ca}^{2+}$ buffering effect of indo- 1 is similar between control and hypertrophied myocytes. Table I shows the results of the intracellular $\mathrm{Ca}^{2+}$ calibration. Under the baseline experimental conditions of this study, systolic and diastolic $\left[\mathrm{Ca}^{2+}\right]_{\mathrm{i}}$ levels were similar between control and hypertrophied myocytes.

Effects of 2DG in isolated myocytes. The effects of partial metabolic inhibition with 2DG under oxygenated conditions are illustrated in Fig. 1. Exposure to 2DG caused a more prominent upward shift in the diastolic cell position and slowing of myocyte relengthening in hypertrophied myocytes compared with control myocytes. Whereas diastolic $\left[\mathrm{Ca}^{2+}\right]_{\mathrm{i}}$ increased in both groups during 2DG superfusion, the diastolic $\left[\mathrm{Ca}^{2+}\right]_{i}$ of the hypertrophied myocytes did not show a greater increase compared with the control myocytes. Fig. 2 summarizes the effects of 2DG on cell motion and $\left[\mathrm{Ca}^{2+}\right]_{\mathrm{i}}$ in 5 control myocytes and 10 hypertrophied myocytes. Cell position data were normalized using baseline values such that the baseline position of an edge of myocyte at end-diastole is defined as 0 , and at end-systole as 100. Fig. 3 summarizes the changes in the amplitude of cell motion during 2DG exposure. While the amplitude of cell shortening was not changed significantly in control myocytes compared to baseline, the amplitude of cell shortening in hypertrophied myocytes decreased significantly during 2DG superfusion $(P<0.02)$. The mechanism of this reduction in amplitude of cell shortening was the failure of the hypertrophied myocytes to relengthen to baseline diastolic cell length rather than a reduction in the absolute extent of systolic shortening. Exposure to 2DG caused a significant increase in the diastolic cell position in both groups compared with baseline $(P<0.001)$, indicating an impaired extent of relaxation. Hypertrophied myocytes, however, showed a more rapid and prominent upward shift in diastolic cell position compared with control myocytes $(\Delta 144 \pm 28$ vs. $\Delta 55 \pm 15 \%$ of baseline at time $15 \mathrm{~min}, P<0.02$ ) which was apparent within 3-5 min of superfusion with 2DG. Exposure to 2DG caused no change in peak systolic $\left[\mathrm{Ca}^{2+}\right]_{\mathrm{i}}$ in either group. In contrast, diastolic $\left[\mathrm{Ca}^{2+}\right]_{\mathrm{i}}$ increased during the 2DG superfusion in both groups relative to baseline $(P<0.001)$; however, there was no significant difference in diastolic $\left[\mathrm{Ca}^{2+}\right]_{\mathrm{i}}$ between hypertrophied and control myocytes $(218 \pm 34$ vs. $183 \pm 29$ NM, NS) (Fig. 4).

Effects of iodoacetate in isolated myocytes. The results of iodoacetate protocol are summarized in Fig 5. Diastolic cell position was significantly increased in both groups compared with baseline $(P<0.05)$. Hypertrophied myocytes, however, showed a greater increase in diastolic cell position compared with control myocytes $(106 \pm 39$ vs. $9 \pm 5 \%$ of baseline at time 15 $\min , P<0.05)$. Diastolic $\left[\mathrm{Ca}^{2+}\right]_{\mathrm{i}}$ was increased significantly in both groups relative to baseline $(P<0.05)$. However, there was no significant difference between hypertrophied and control myocytes $(200 \pm 30$ vs. $174 \pm 23 \mathrm{nM}$ at time $15 \mathrm{~min}$, respectively).

A representative tracing illustrating the effect of $20 \mathrm{mM}$ BDM on the reversal of partial contracture in hypertrophied myocytes exposed to 2DG $(n=3)$ is shown in Fig. 6. Increased diastolic cell position was restored toward baseline by $87 \pm 3 \%$ with the superfusion of $20 \mathrm{mM}$ BDM.

To exclude excess compartmentation of indo-1 within intracellular organelles as a factor confounding the assessment of $\mathrm{Ca}^{2+}$-sensitive fluorescence, we examined the time course of the decline of fluorescence after abrupt exposure of indo-1 loaded 
Baseline

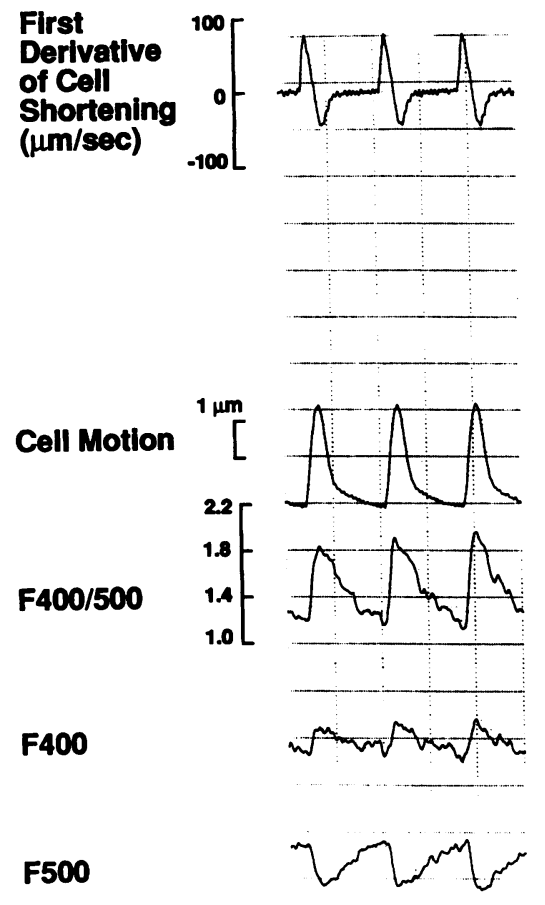

2DG
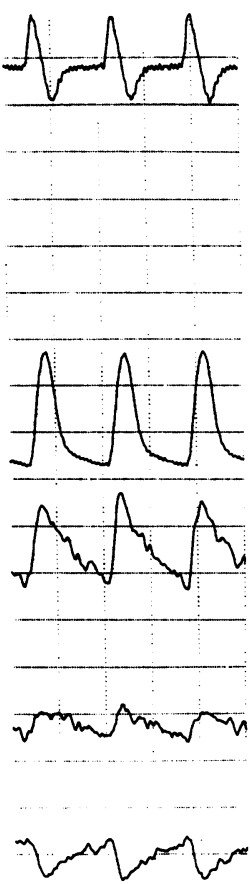

2DG
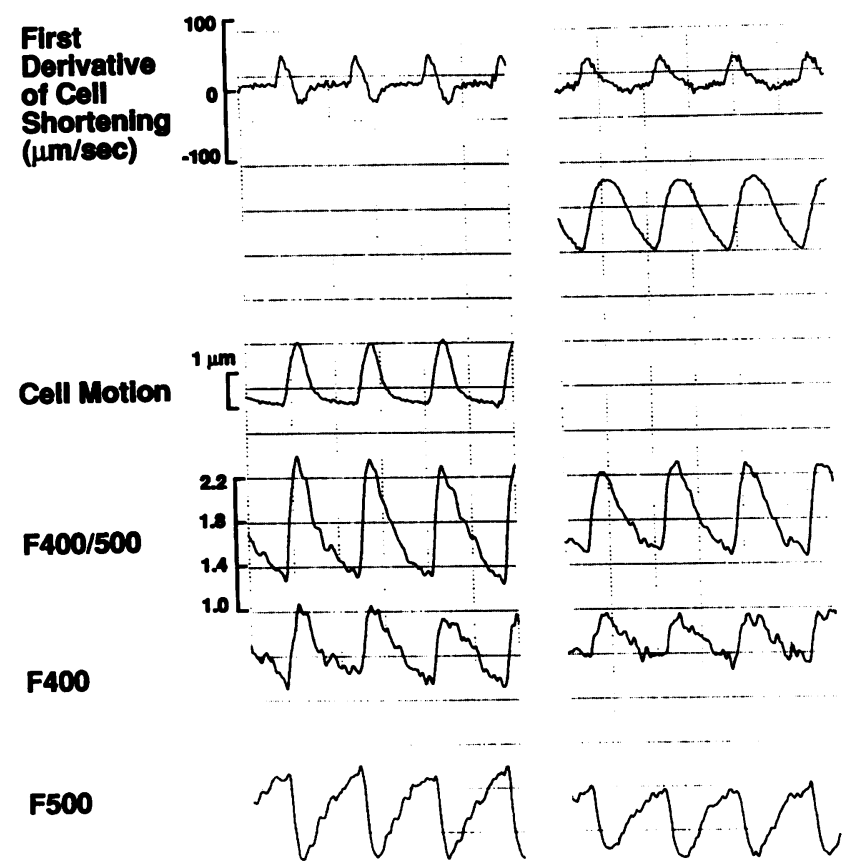

Figure 1. Representative traces of first derivative of cell motion, cell motion, $\left[\mathrm{Ca}^{2+}\right]_{\mathrm{i}}$-sensitive ratio of fluorescence intensities of 400 to 500 $\mathrm{nm}(F 400 / 500)$, and fluorescence intensities at 400 and $500 \mathrm{~nm}$ during baseline condition and at the end of 2DG superfusion in a control myocyte (upper panel) and in a hypertrophied myocyte (lower panel). These representative recordings were selected from the control $(n=5)$ and hypertrophied $(n=10)$ myocyte studies. Tracings are displayed with the convention that systolic myocyte shortening is displayed as an upward deflection of the cell motion trace. Note the prominent upward shift of diastolic cell position and slowing of the time course of cell relengthening, consistent with impairment of relaxation in the hypertrophied myocyte.

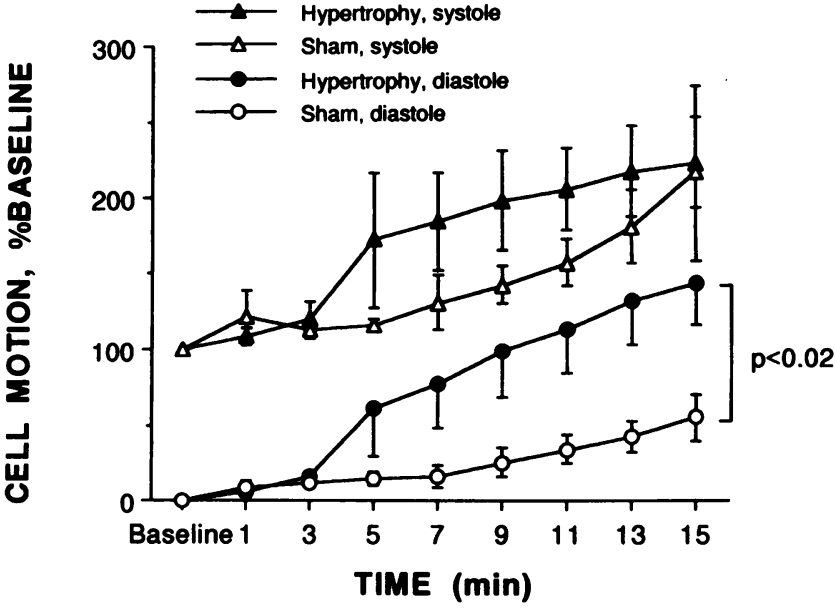

Figure 2. Average effects of exposure to 2DG on cell motion in hypertrophied $(n=10)$ and age-matched control myocytes $(n=5)$. Values are normalized relative to baseline for each myocyte. Time represents the elapsing time after the initiation of 2DG superfusion. Values are mean \pm SEM. Whereas there was no difference in peak-systolic cell motion between the groups, the hypertrophied myocytes showed a more rapid and prominent increase in diastolic cell position, indicative of impaired relaxation.

myocytes to a concentration of digitonin sufficient to permeabilize the sarcolemmal membrane without disrupting organelles (18). Representative tracings of fluorescence intensity from both control and hypertrophied myocytes during the compartmentation study are shown in Fig. 7. Exposure to digitonin caused the rapid decline of fluorescence intensity in both groups. Residual fluorescence intensity measured at $400 \mathrm{NM}$ was $10.9 \pm 2.0$ vs. $11.9 \pm 0.7 \%$ of peak intensity $2 \mathrm{~min}$ after exposure to digitonin, and $4.1 \pm 0.4$ vs. $5.5 \pm 0.8 \% 3 \mathrm{~min}$ after the exposure to digitonin in the control $(n=3)$ and hypertrophied ( $n$

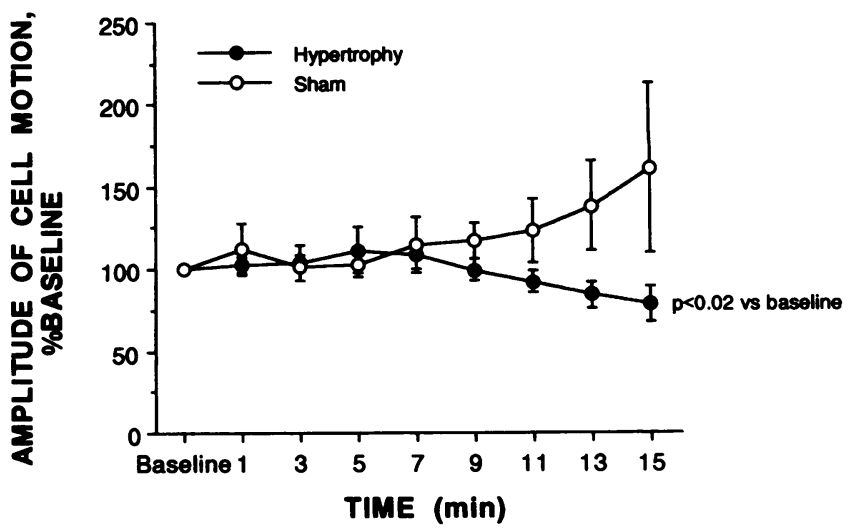

Figure 3. Average effects of 2DG on amplitude of cell shortening in hypertrophied $(n=10)$ and control $(n=5)$ myocytes. Values are normalized relative to baseline for each myocyte. Time represents the elapsing time after the initiation of 2DG superfusion. In comparison with the normal myocyte (Sham), 2DG exposure caused a reduction in amplitude of cell shortening in the hypertrophied myocytes. As shown in Fig. 2, this depression of the amplitude of cell shortening was related to incomplete relaxation during diastole which limited the amplitude of systolic shortening in the hypertrophied myocytes. Values are mean \pm SEM. 


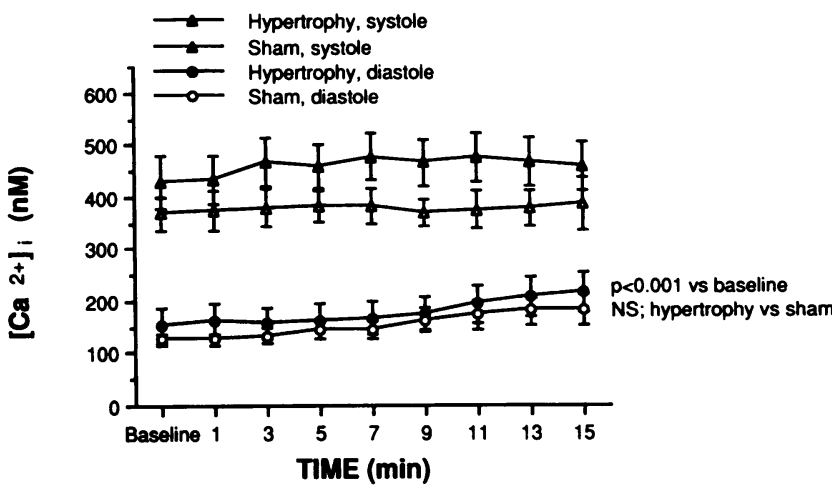

Figure 4. Average effects of exposure to 2DG on peak-systolic and end-diastolic $\left[\mathrm{Ca}^{2+}\right]_{i}$. Time represents the elapsing time after the initiation of 2DG superfusion. Values are mean \pm SEM. There was no significant change in peak-systolic $\left[\mathrm{Ca}^{2+}\right]_{\mathrm{i}}$. Exposure to 2DG caused a similar increase in diastolic $\left[\mathrm{Ca}^{2+}\right]_{\mathrm{i}}$ in both groups.

= 3) myocytes, respectively. There was no significant difference between the control and hypertrophied myocytes.

Effects of $2 D G$ in intact hearts. To assure that the response of isolated myocytes was representative of intact control and hypertrophied hearts, the 2DG perfusion protocol was repeated
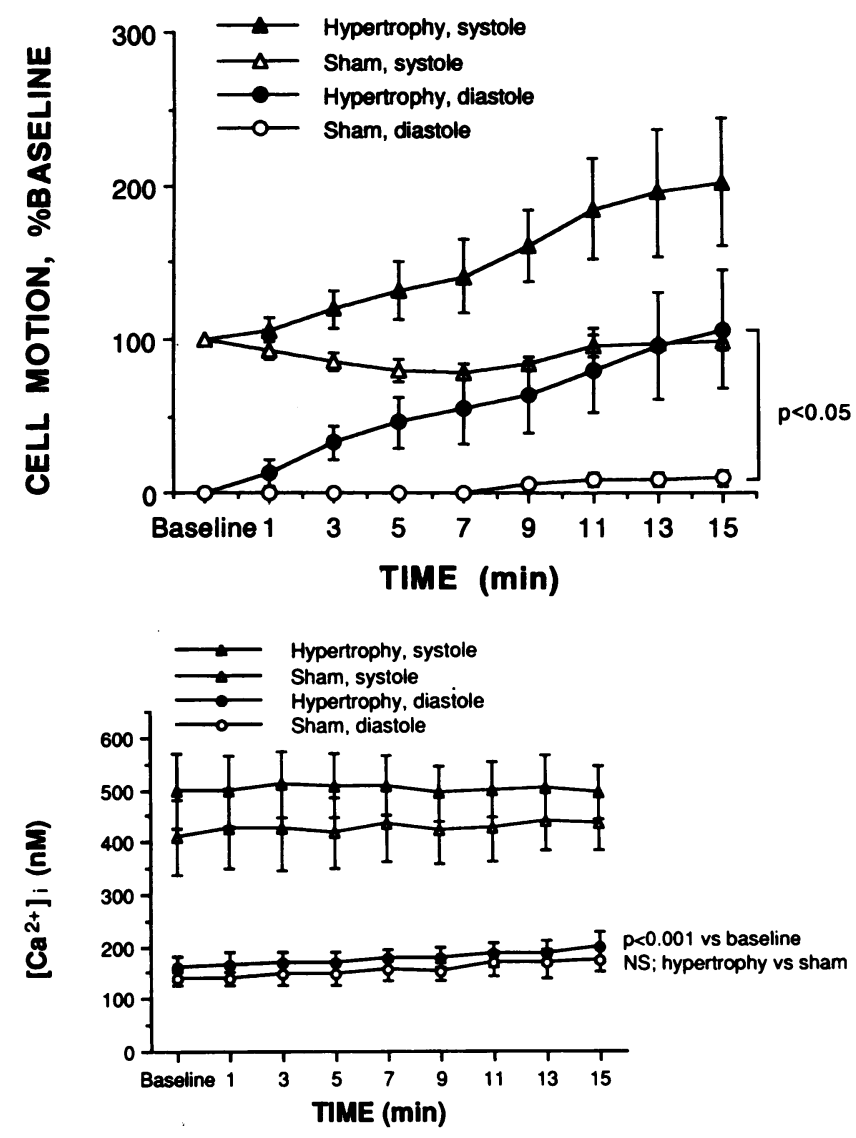

Figure 5. Average effects of iodoacetate on cell motion (top) and $\left[\mathrm{Ca}^{2+}\right]_{\mathrm{i}}$ (bottom) in hypertrophied and control myocytes. Cell motion data are normalized relative to baseline for each monocyte. Time represents the elapsing time after initiation of iodoacetate superfusion. Values are mean \pm SEM
Table II. Left Ventricular Function and High Energy Phosphate Content

\begin{tabular}{lcc}
\hline & Baseline & 2DG \\
\hline LV dev P (mmHg) & & \\
$\quad$ Control & $112 \pm 2$ & $87 \pm 2$ \\
LVH & $168 \pm 4^{*}$ & $94 \pm 10^{*}$ \\
LV dev P/g (mmHg/g) & & \\
Control & $90 \pm 2$ & $69 \pm 1$ \\
LVH & $99 \pm 5$ & $56 \pm 7$ \\
LVEDP (mmHg) & & \\
Control & $10.3 \pm 0.3$ & $19.0 \pm 1.8$ \\
LVH & $10.9 \pm 0.3$ & $35.3 \pm 3.2^{\ddagger}$ \\
Tau (ms) & & \\
$\quad$ Control & $25 \pm 1$ & $55 \pm 6$ \\
LVH & $24 \pm 1$ & $92 \pm 6^{\ddagger}$ \\
ATP $(\mu$ mol/g dry weight) & & \\
Control $(n=5 / 7)$ & $19.1 \pm 0.5$ & $11.1 \pm 0.9$ \\
LVH & $17.6 \pm 0.3$ & $7.1 \pm 0.8^{\ddagger}$ \\
Phosphocreatine $(\mu \mathrm{mol} / \mathrm{g}$ dry weight) & & \\
$\quad$ Control & $24.1 \pm 0.8$ & $8.7 \pm 1.0$ \\
LVH & $20.1+0.7^{*}$ & $3.2+0.7^{\ddagger}$
\end{tabular}

Mean \pm SEM. $* P<0.05 \mathrm{LVH}$ versus control hearts. ${ }^{\ddagger} P<0.01 \mathrm{LVH}$ versus control hearts. LVH, hypertrophied hearts from rats eight weeks after aortic banding ( $n=7)$; Control, hearts from sham-operated, agematched control hearts $(n=7)$; LV systolic $\mathrm{P}$, left ventricular systolic pressure; LVEDP, isovolumic left ventricular end-diastolic pressure; LV $\operatorname{dev}$ P, LV developed pressure (absolute values and per gram left ventricular weight); Tau, time constant of left ventricular pressure decay; ATP, adenosine triphosphate. The baseline ATP and phosphocreatine measurements were obtained in an additional five LVH and control hearts subjected to $30 \mathrm{~min}$ of perfusion with the baseline perfusate solution containing glucose in the absence of 2DG.

in additional isolated buffer-perfused hypertrophied $(n=7)$ and control $(n=7)$ hearts (Table II). Under baseline isovolumic conditions of left ventricular end-diastolic pressure adjusted to $10 \mathrm{mmHg}$ and identical coronary flow per gram, systolic developed pressure normalized for LV mass $(99 \pm 5$ vs. $90 \pm 2 \mathrm{mmHg}$ / gm) and the relaxation time constant tau $(24 \pm 1$ vs. $25 \pm 1 \mathrm{~ms})$ were similar in the hypertrophied age-matched control hearts. In response to oxygenated perfusion with the 2DG perfusate, the hypertrophied versus control hearts showed a greater decline in developed pressure ( $56 \pm 6$ vs. $78 \pm 2 \%$ of baseline, $P<0.01$ ). In the hypertrophied versus control hearts, 2DG caused severe deterioration of diastolic function evident as a marked increase in isovolumic left ventricular end-diastolic pressure ( $35 \pm 3$ vs. $19 \pm 2 \mathrm{mmHg}, P<0.005)$ and prolongation of the relaxation time constant $(92 \pm 8$ vs. $55 \pm 6 \mathrm{~ms}, P<0.005)$. There was no change in coronary perfusion pressure in either group, excluding changes in pressurization of the vasculature ("turgor") as the mechanism of the rise in isovolumic diastolic pressure in the hypertrophy group.

Left ventricular ATP and phosphocreatine contents are shown in Table II. Under baseline perfusion conditions, ATP contents were similar whereas phosphocreatine contents were significantly lower in the hypertrophied hearts compared with the age-matched control groups. In response to oxygenated 2DG perfusion, ATP declined to 36 vs. $58 \%$ of baseline levels in the hypertrophied versus control hearts, and phosphocreatine 


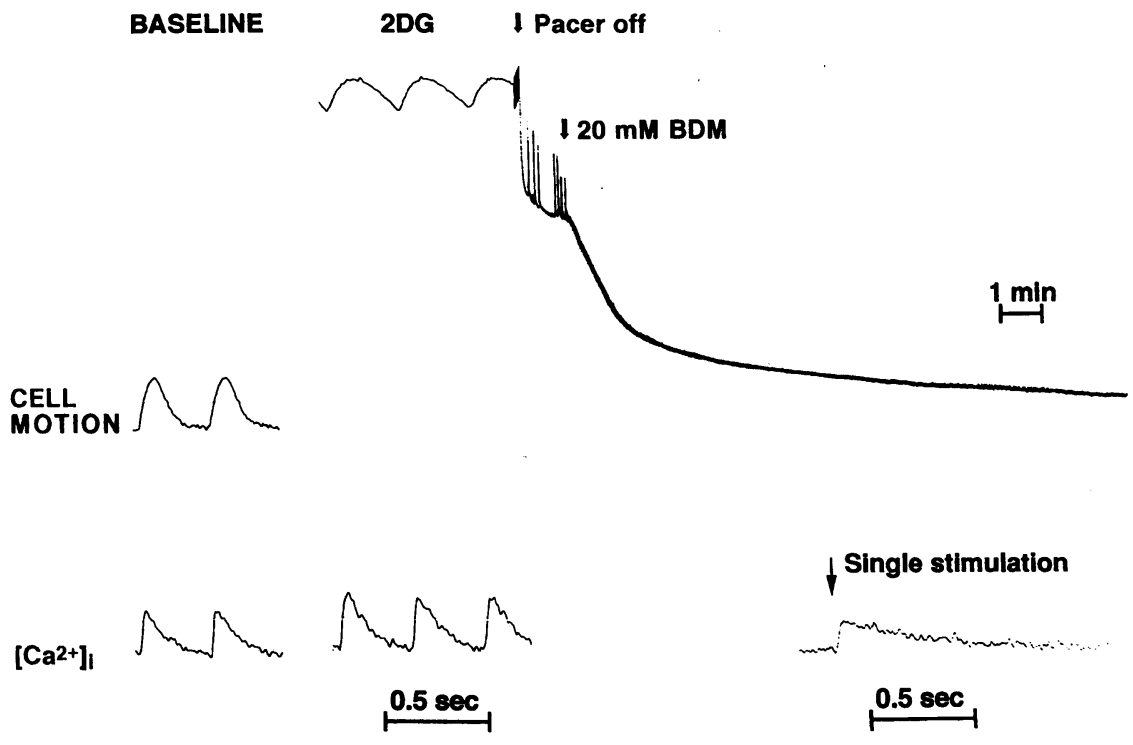

Figure 6. A representative tracing showing the effect of BDM on increased diastolic cell position due to 2DG in a hypertrophied myocyte. After the pacer was stopped, diastolic cell position was decreased, suggesting the contribution of incomplete relaxation to the increased diastolic cell position. BDM restored the increased diastolic cell position toward baseline, supporting the notion that the increased diastolic cell position caused by $2 \mathrm{DG}$ is mainly due to enhanced interaction between actin and myosin, not to irreversible rigor. A single electrical stimulation after BDM superfusion elicited a calcium transient accompanied by no cell contraction.

declined to 16 vs. $41 \%$ of baseline values in the hypertrophied versus control hearts. There were no differences in the frozen/ dry weight ratios between the groups.

\section{Discussion}

These experiments demonstrate that glycolytic inhibition by 2DG causes greater impairment of diastolic relaxation in welloxygenated hypertrophied myocytes compared with control myocytes. The novel finding of the present study that 2DG caused more severe impairment of relaxation in isolated hypertrophied myocytes as well as in isolated perfused hypertrophied hearts indicates that the defect is related to impaired crossbridge dissociation, rather than factors of cardiac geometry or the connective tissue ultrastructure which are confounding factors that modify relaxation in intact hypertrophied hearts. Diastolic intracellular $\mathrm{Ca}^{2+}$ levels were similar in the hypertrophied and control myocytes at baseline, and $2 \mathrm{DG}$ caused a progressive increase in diastolic $\left[\mathrm{Ca}^{2+}\right]_{\mathrm{i}}$ in both groups. However, the difference in the magnitude of the impaired diastolic relaxation could not be explained by a more severe diastolic $\mathrm{Ca}^{2+}$ overload in the hypertrophied myocytes. These findings seriously challenge the notion previously advanced by us and others that the susceptibility of the hypertrophied heart to diastolic dysfunction during energy deprivation can be explained solely by the mechanism of an exaggerated increase in diastolic $\mathrm{Ca}^{2+}$ relative to normal hearts (4-7).

The ascending aortic-banded rat model of concentric left ventricular hypertrophy used in the present experiment has been extensively characterized in our prior studies $(6,12,13,30$, 31 ). At this stage of pressure overload hypertrophy, contractile properties are reasonably well maintained, with a slight decrease in fractional shortening but a significant decrease in the rate of shortening relative to control myocytes. In rat ventricle with chronic pressure overload, $\alpha$ (V1) myosin heavy chain is replaced by $\beta$ (V3) myosin heavy chain, an isoform shift which correlates with a reduced velocity of cardiac muscle shortening (32). Recent molecular biology studies have confirmed that this isoform shift is present at this stage after aortic banding in our model (31). Thus, our observations regarding the altered time course and velocity of systolic cell shortening may be due in part to the myosin heavy chain isoform shift in the hypertrophied myocytes due to chronic pressure overload. Altered intracellular $\mathrm{Ca}^{2+}$-handling might be an additional mechanism responsible for an altered time course of cell shortening. The results in the present study, however, showed no difference in either time to peak systolic $\left[\mathrm{Ca}^{2+}\right]_{\mathrm{i}}$ or time to $50 \%$ decline in $\left[\mathrm{Ca}^{2+}\right]_{\mathrm{i}}$ from peak between hypertrophied and control myocytes at this stage

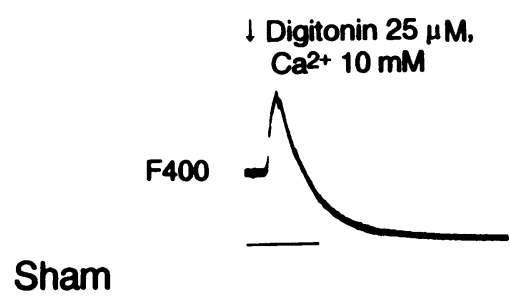

$\mathbf{F} 500$

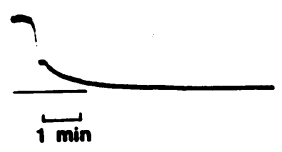

\section{Hypertrophy}

F400

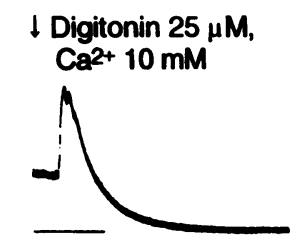

F500

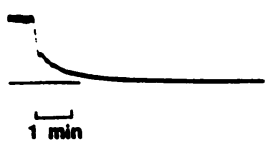

Figure 7. Changes in intensity of fluorescence at 400 and $500 \mathrm{~nm}$ in myocytes loaded with indo$1 \mathrm{AM}$ exposed to $25 \mu \mathrm{M}$ digitonin and $10 \mathrm{mM}$ $\mathrm{CaCl}_{2}$ to estimate dye compartmentation. The horizontal lines represent background level of fluorescence from unloaded myocytes. 
after aortic banding under well-oxygenated normothermic conditions. These findings are congruent with the observation in the present study that the relaxation time constant of left ventricular pressure decay is similar in the isolated perfused hypertrophied hearts and age-matched controls at this stage after aortic banding.

In this study, using normal rat myocytes, we showed that both diastolic cell position and diastolic $\left[\mathrm{Ca}^{2+}\right]_{i}$ were increased by $2 \mathrm{DG}$ compared with baseline. The time course and magnitude of the increase in diastolic $\left[\mathrm{Ca}^{2+}\right]_{\mathrm{i}}$ and impairment of relaxation are consistent with the observation of Ikenouchi et al. (11) who showed that glycolytic inhibition by 2DG causes increases in both diastolic cell position and $\left[\mathrm{Ca}^{2+}\right]_{\mathrm{i}}$ in cultured chick embryonic cell and paced adult rabbit ventricular myocytes. Further, they demonstrated that repetitive depolarization and cell contraction is a prerequisite for 2DG-induced impairment of relaxation which does not occur in myocytes which are quiescent (11). In their experiments and in our study, the degree of increase in $\left[\mathrm{Ca}^{2+}\right]_{i}$ and that of diastolic cell position were concordant in control myocytes from normal rabbits and rats. This observation lends support to the notion that impairment of cytosolic calcium homeostasis caused by 2DG contributes to impaired diastolic relaxation in normal myocytes.

However, an unexpected finding in our study was that there was no difference in the time course or magnitude of increase in diastolic $\mathrm{Ca}^{2+}$ levels in the hypertrophied and normal myocytes in response to $2 \mathrm{DG}$. Thus, the rapid and prominent impairment in diastolic relaxation in the hypertrophied myocytes during partial metabolic inhibition cannot be attributed to a greater degree of diastolic $\mathrm{Ca}^{2+}$ overload. The ability of the hypertrophied myocytes to regulate diastolic $\left[\mathrm{Ca}^{2+}\right]_{\mathrm{i}}$ similar to normal myocytes is at first surprising in the face of prior molecular biology studies which have shown reduced message levels and activity of the sarcoplasmic reticulum $\mathrm{Ca}^{2+}$-ATPase pumps and the regulatory protein phospholamban in hypertrophied rat and human hearts $(3,33)$. In turn, these quantitative changes in gene expression have been conceptually linked with the observation of prolongation of the time course of decay of the $\mathrm{Ca}^{2+}$ transient in muscles obtained from hearts at a late stage of hypertrophy with failure (34). Our observations in this study suggest that attribution of diastolic dysfunction of hypertrophied hearts during energy deprivation to exaggerated cytosolic $\mathrm{Ca}^{2+}$ overload may be overly simplistic. In this regard, molecular biology studies from our laboratory using Northern blot and PCR techniques have shown that sarcoplasmic reticular $\mathrm{Ca}^{2+}$ ATPase message levels are similar in aortic-banded hearts at this stage of hypertrophy relative to controls, and only decline at a much later stage of hypertrophy during the transition to failure (31). Taken together, these observations challenge the notion that the susceptibility of the heart with early adaptive hypertrophy to impaired relaxation during energy depletion is explained by the simple mechanism of diastolic $\mathrm{Ca}^{2+}$ overload.

Limitations. A potential limitation of this study is that acetoxymethyl fluorescent-indicators like indo 1-AM and fura 2AM can promote dye compartmentation in intracellular organelles such as the mitochondria $(22,35)$. We demonstrated, however, that the degree of dye compartmentation is small in the experimental conditions of this study and is not significantly different between control and hypertrophied myocytes. Therefore, differences in indo-1 compartmentation between control and hypertrophied myocytes are not likely to account for the observation that the increase in $\left[\mathrm{Ca}^{2+}\right]_{\mathrm{i}}$ during $2 \mathrm{DG}$ exposure was not greater in the hypertrophied cells. These data do not exclude the possibility that total $\mathrm{Ca}^{2+}$ may distribute from the cytosol to the mitochondria differently in normal and hypertrophied myocytes giving rise to the same indo 1 fluorescence signal.

Calcium calibration experiments also showed that there was no difference in absolute values of either end-diastolic or peaksystolic $\left[\mathrm{Ca}^{2+}\right]_{\mathrm{i}}$ under baseline conditions between control and hypertrophied cells. It should be noted that our studies were done in normothermic rat myocytes at a pacing rate of $3 \mathrm{~Hz}$ and in the presence of a relatively low perfusate $\left[\mathrm{Ca}^{2+}\right]_{\mathrm{i}}$ of 1.2 $\mathrm{mM}$. Several investigators have reported calibrated values of $\left[\mathrm{Ca}^{2+}\right]_{\mathrm{i}}$ in adult rat myocytes. End-diastolic $\left[\mathrm{Ca}^{2+}\right]_{\mathrm{i}}$ values range from $75-140 \mathrm{NM}(22,36)$ whereas peak-systolic values of $\left[\mathrm{Ca}^{2+}\right]_{\mathrm{i}}$ are more variable and range from $\sim 480-1100 \mathrm{NM}$ $(22,37)$. The calibrated values of $\left[\mathrm{Ca}^{2+}\right]_{i}$ in the present study are consistent with those of earlier studies. The variation in systolic $\left[\mathrm{Ca}^{2+}\right]_{\mathrm{i}}$ levels in prior studies may be related to differences in experimental conditions, including temperature, perfusate $\left[\mathrm{Ca}^{2+}\right]$, and the presence of a rate-related "negative staircase" effect in rat myocytes.

Our observations implicate an increase in myofilament responsiveness to $\mathrm{Ca}^{2+}$ to account for the greater impairment of diastolic relaxation in hypertrophied myocytes relative to control myocytes in the presence of a similar increase in $\left[\mathrm{Ca}^{2+}\right]_{i}$ during 2DG exposure. Ikenouchi et al. (11) have shown that exposure to 2DG does not cause a change in intracellular $\mathrm{pH}$ under conditions similar to this experiment. However, 2DG serves as $\mathrm{P}_{\mathrm{i}}$ " "sink" within the myocyte as the result of the irreversible phosphorylation of 2DG to 2DG-6-phosphate (11, $38,39)$. Differences in the depletion of intracellular $P_{i}$ could potentially contribute to the difference in cell motion and relaxation in the hypertrophied versus normal myocytes since $P_{i}$ decreases $\mathrm{Ca}^{2+}$ responsiveness of the myofilaments $(40,41)$. To investigate this possibility, we examined the effects of an alternative compound which inhibits glycolysis, iodoacetate, in the absence of the confounding action of promoting a $P_{i}$ sink (25). Exposure to iodoacetate caused a change in cell motion and $\left[\mathrm{Ca}^{2+}\right]_{\mathrm{i}}$ similar to that induced by $2 \mathrm{DG}$. During exposure to iodoacetate, there was greater impairment of relaxation in hypertrophied myocytes whereas the increase in diastolic $\left[\mathrm{Ca}^{2+}\right]_{\mathrm{i}}$ was similar to the normal cells. It is unlikely, therefore, that the severe changes in relaxation caused by 2DG in hypertrophied myocytes relative to control myocytes are explained by a greater depletion of intracellular $P_{i}$ due to phosphorylation of 2DG. Even though iodoacetate elicits a significant increase in diastolic cell position in control myocytes, the degree of upward shift of diastolic cell position was less prominent compared with that caused by 2DG in control myocytes. The mechanism for this is unclear and may relate to differences in the magnitude of glycolytic inhibition in response to 2DG and iodoacetate.

To determine if the impairment of myocyte lengthening in response to 2DG was irreversible, we also examined the effects of BDM on cell motion in hypertrophied myocytes after the development of severely impaired relaxation during 2DG exposure. BDM decreases $\left[\mathrm{Ca}^{2+}\right]_{\mathrm{i}}$-induced contraction of myofilaments during persistent crossbridge cycling $(26,27)$, and Nichols and Lederer (42) have shown that BDM can prevent the development of rigor but cannot reverse already formed rigor bonds. In this experiment, BDM reversed $87 \%$ of the contracture due to 2DG exposure. This observation suggests that the severe impairment of relaxation of the hypertrophied cells during 2DG 
exposure is in part related to a change in myofilament $\mathrm{Ca}^{2+}$ -responsiveness rather than $\mathrm{Ca}^{2+}$-insensitive rigor. Alternatively, the observation that BDM did not completely normalize relaxation is consistent with a few rigor bridges acting in series with cycling crossbridges. In addition, the high concentration of BDM used may have effects in addition to those at the level of the crossbridge, including changes in the amplitude of $\mathrm{Ca}^{2+}$ transient.

Another potential limitation is that experiments were performed on individual myocytes raising the issue as to whether the isolated myocytes are representative of the intact hearts from which they are isolated. Furthermore, it is also possible that the shortening behavior of relatively unloaded isolated myocytes may not simulate the response of the loaded intact heart to glycolytic inhibition. To address this, additional age-matched control and hypertrophied hearts from aortic-banded rats at an identical stage were studied in an isolated isovolumic perfused heart preparation and subjected to the baseline and 2DG perfusion protocols used in the isolated myocyte study. In these hearts, indices of isovolumic force development were measured rather than unloaded cell shortening. In response to 2DG perfusion for $8 \mathrm{~min}$, the hypertrophied hearts in comparison with the control hearts developed severe elevation of isovolumic left ventricular end-diastolic pressure and prolongation of the relaxation time constant of left ventricular pressure decay. Left ventricular systolic developed pressure was also more depressed in the hypertrophied hearts, due to incomplete relaxation to baseline end-diastolic pressure. These findings support the notion that the severe impairment of myocyte lengthening observed in the isolated hypertrophied myocytes is characteristic of the effects of glycolytic inhibition in the intact hypertrophied heart, in which severe impairment of relaxation is prominent.

To further the relationship between diastolic dysfunction and high energy phosphate depletion in response to 2DG, myocardial ATP and phosphocreatine contents were measured in the hypertrophied and control hearts perfused with 2DG. Under baseline perfusion conditions ATP content was similar in both groups, whereas phosphocreatine levels were lower in the hypertrophied hearts consistent with observations in other models of hypertrophy $(1,2)$. In normal and hypertrophied well-oxygenated hearts supplied with acetate as substrate for mitochondrial oxidative phosphorylation, 2DG may cause a reduction in ATP levels by trapping of $P_{i}$, leading to reduced phosphorylation and washout of creatine substrate with secondary impairment of ATP synthesis via the creatine kinase pathway $(1,25)$. However, we observed that both the absolute reduction and change relative to baseline of ATP and phosphocreatine contents were greater in the hypertrophied hearts compared with the controls in response to metabolic inhibition with 2DG under oxygenated conditions.

These findings are consistent with other experiments suggesting an altered integration of energy synthesizing pathways in hypertrophied myocardium including depressed activity of the creatine kinase pathway and an enhanced dependence on glycolytic metabolism $(1,2,7,8,43-45)$. The increased dependence of hypertrophied myocardium for glucose utilization may be related to an increased activity of glycolytic enzymes $(8,46)$ as well as a switch to the fetal pattern of enhanced expression of the GLUT 1 basal transporter relative to the GLUT 4 insulinresponsive transporter (47). Taken together, these observations lend support that utilization of glucose as an energy substrate in hypertrophied myocardium may simulate the immature pat- tern of enhanced dependence on glycolysis for cardiac ATP production which has been observed in neonatal hearts (48) and embryonic cultured myocytes (49).

Potential mechanisms of impaired relaxation. Mechanisms distinct from ATP-dependent rigor merit consideration. The absolute level of ATP in the hypertrophied hearts in response to 2DG was in the range of $7 \mu \mathrm{mol}$ per gram dry weight, which is higher than the levels usually associated with ATP-dependent rigor during prolonged ischemia. This finding is consistent with the results of the BDM experiment in the isolated hypertrophied myocytes, which suggested that the impaired myocyte lengthening induced by 2DG was largely reversible, implicating persistent $\mathrm{Ca}^{2+}$-dependent crossbridge cycling. As recently reviewed by Winegrad et al. (50), studies in skinned cardiac fibers have shown that $\mathrm{Ca}^{2+}$-activated force increases when ATP concentration falls to levels of $<1 \mathrm{mM} / 1$ to about $50 \mu \mathrm{mol} / 1$, due to an allosteric effect of low ATP levels on troponin affinity for $\mathrm{Ca}^{2+}$. In our experiments, ATP content was measured and actual cytosolic ATP concentration is not known. Further, skinning of cardiac fibers itself appears to modify myofilament $\mathrm{Ca}^{2+}$ sensitivity (51). Thus, the magnitude of reduction of ATP which is sufficient to exert an allosteric effect on $\mathrm{Ca}^{2+}$ sensitivity in the intact nonhyperpermeabilized myocyte is not known.

Increases in MgADP could also modify $\mathrm{Ca}^{2+}$ sensitivity and potentially contribute to the exaggerated impairment of relaxation in hypertrophied myocardium, in light of recent insight into the altered integration of energy-synthesizing pathways in hypertrophied myocardium. Recent studies in animal models of hypertrophy, including the present aortic-banded rat model, have consistently demonstrated depressed activity of the creatine kinase system, which serves the dual function of rapid resupply of ATP during high demand conditions and providing the "buffering" function of maintaining low ADP concentrations (1, 43-45). Recent studies suggest that small increases in ADP may modify myofilament $\mathrm{Ca}^{2+}$ sensitivity. Current modeling of crossbridge kinetics supports the presence of three states of crossbridge activation including unattached, weakly bound and force-generating states (52). Hoar et al. (53) have shown that increases in MgADP within the $\mathrm{mM}$ range increase maximum tension and myofilament $\mathrm{Ca}^{2+}$ sensitivity in skinned rabbit soleus muscle, implicating prolongation of the force-generating state of crossbridge interaction. MgADP may also modify $\mathrm{Ca}^{2+}$ affinity for troponin (54). Recent studies using both rat cardiac and skeletal muscle confirm that the addition of MgADP in a concentration as low as $25 \mu \mathrm{M}$ inhibits the sliding velocity of actin filaments on myosin and reduces the rate of crossbridge detachment (55). Thus, a potential mechanism to explain the severe impairment of relaxation in the hypertrophied myocytes and intact hearts during 2DG perfusion in the presence of ATP levels sufficient to prevent rigor is the development of a higher concentration of ADP sufficient to prolong the forcegenerating state of crossbridge attachment. Future experiments using technique such as magnetic resonance spectroscopy to directly calculate ADP concentration will be needed to confirm this hypothesis.

In summary, glycolytic inhibition by 2DG caused more severe impairment of diastolic relaxation in comparison with normal myocytes. However the greater impairment of diastolic relaxation in the hypertrophied myocytes was not explained by more severe diastolic $\left[\mathrm{Ca}^{2+}\right]_{\mathrm{i}}$ overload, implicating an increase in myofilament $\mathrm{Ca}^{2+}$ sensitivity. We speculate that the severe impairment of relaxation in hypertrophied myocytes in response 
to glycolytic inhibition may be related to altered integration of energy-synthesizing pathways and complex interaction between elevated ADP and reduced ATP levels on prolongation of the force-generating active crossbridge state.

\section{Acknowledgments}

We greatly appreciate the expert surgical assistance of Mr. S. Ngoy in the preparation of the aortic-banded rat colonies. We also appreciate the helpful comments and criticisms of Dr. J. P. Morgan. We also appreciate the secretarial and administrative assistance of Ms. B. Zillman.

This work was supported in part by National Heart, Lung, and Blood Institute Grants HL-38189 (B. H. Lorell and Y. Kagaya), HL-44431 (B. H. Lorell), HL-30478 (W. H. Barry), and an Established Investigatorship and a national Grant-in-Aid of the American Heart Association (B. H. Lorell).

\section{References}

1. Ingwall, J. S. 1993. Is cardiac failure a consequence of decreased energy reserve? Circulation. 87:58-62.

2. Ingwall, J. S., M. F. Kramer, M. A. Fifer, B. H. Lorell, R. Shemin, W. Grossman, and P. D. Allen. 1985. The creatine kinase system in normal and diseased human myocardium. N. Engl. J. Med. 313:1050-1054.

3. De la Bastie, D., D. D. Levitsky, L. Rappaport, J. J. Mercadier, F. Marotte, C. Wisnewsky, V. Brovkovich, K. Schwartz, and A.-M. Lompre. 1990. Function of the sarcoplasmic reticulum and expression of its $\mathrm{Ca}^{2+}$-ATPase gene in pressure overload induced cardiac hypertrophy in the rat. Circ. Res. 66:554-564.

4. Lorell, B. H., L. F. Wexler, S. Momomura, E. O. Weinberg, and C. S. Apstein. 1986. The influence of pressure overload left ventricular hypertrophy on diastolic properties during hypoxia in isovolumically contracting rat hearts. Circ. Res. 58:653-663.

5. Wexler, L. F., B. H. Lorell, S. Momomura, E. O. Weinberg, J. S. Ingwall, and C. S. Apstein. 1988. Enhanced sensitivity to hypoxia-induced diastolic dysfunction in pressure-overload left ventricular hypertrophy in rats: role of highenergy phosphate depletion. Circ. Res. 62:766-775.

6. Eberli, F. R., C. S. Apstein, S. Ngoy, and B. H. Lorell. 1992. Exacerbation of left ventricular ischemic diastolic dysfunction by pressure overload hypertrophy: modification by specific inhibition of cardiac angiotensin converting enzyme. Circ. Res. 70:931-943.

7. Cunningham, M. J., C. S. Apstein, E. O. Weinberg, W. M. Vogel, and B. H. Lorell. 1990. Influence of glucose and insulin on the exaggerated diastolic and systolic dysfunction of hypertrophied rat hearts during hypoxia. Circ. Res. 66:406-415.

8. Bishop, S. P., and R. A. Altschuld. 1970. Increased glycolytic metabolism in cardiac hypertrophy and congestive heart failure. Am. J. Physiol. 218:153159.

9. Owen, P., S. Dennis, and L. H. Opie. 1990. Glucose flux rate regulates onset of ischemic contracture in globally underperfused rat hearts. Circ. Res. 66:344-354.

10. Weiss, J. N., and S. T. Lamp. 1987. Glycolysis preferentially inhibits ATP-sensitive $\mathrm{K}^{+}$channels in isolated guinea pig cardiac myocytes. Science (Wash. DC). 238:67-69.

11. Ikenouchi, H., O. Kohmoto, M. McMillan, and W. H. Barry. 1991. The contributions of $\left[\mathrm{Ca}^{2+}\right]_{i},[\mathrm{Pi}]_{\mathrm{i}}$, and $\mathrm{pH}_{\mathrm{i}}$ to altered diastolic myocyte tone during partial metabolic inhibition. J. Clin. Invest. 88:55-61.

12. Schunkert, H., V. J. Dzau, S. S. Tang, A. T. Hirsch, C. Apstein, and B. H. Lorell. 1990. Increased rat cardiac angiotensin-converting enzyme activity and mRNA levels in pressure overload left ventricular hypertrophy: effects on coronary resistance, contractility and relaxation. J. Clin. Invest. 86:1913-1920.

13. Weinberg, E. O., F. J. Schoen, D. George, Y. Kagaya, C. R. Benedict, and B. H. Lorell. 1994. Angiotensin-converting enzyme inhibition prolongs survival and modifies the transition to heart failure in rats with pressure overload hypertrophy due to aortic stenosis. Circulation. 90:1410-1422.

14. Capogrossi, M. C., A. A. Kort, H. A. Spurgeon, and E. G. Lakatta. 1986. Single adult rabbit and rat cardiac myocytes retain the $\mathrm{Ca}^{2+}$ - and speciesdependent systolic and diastolic contractile properties of the intact muscle. $J$. Gen. Physiol. 88:589-613.

15. Haddad, J., M. L. Decker, L. Hsieh, M. Lesch, A. M. Samarel, and R. S. Docker. 1988. Attachment and maintenance of adult rabbit cardiac myocytes in primary cell culture. Am. J. Physiol. 255:C19-C27.

16. Grynkiewicz, G., M. Poenie, and R. Y. Tsien. 1985. A new generation of $\mathrm{Ca}^{2+}$ indicators with greatly improved fluorescence properties. J. Biol. Chem. $260: 3440-3450$.
17. duBell, W. H., C. Philips, and S. R. Houser. 1988. A technique for measuring cytosolic free $\mathrm{Ca}^{2+}$ with indo 1 in feline myocytes. In Biology of Isolated Adult Cardiac Myocytes. W. Clark. Elsevier Science Publishing Co., NY. 187-201.

18. Peeters, G. A., V. Hlady, J. H. B. Bridge, and W. H. Barry. 1987. Simultaneous measurement of calcium transients and motion in cultured heart cells. Am. J. Physiol. 253:H1400-H1408.

19. Ikenouchi, H., W. H. Barry, J. H. B. Bridge, E. O. Weinberg, C. S. Apstein, and B. H. Lorell. 1994. Effects of angiotensin II on contractility, intracellular $\mathrm{Ca}^{2+}, \mathrm{I}_{\mathrm{C}}$ and $\mathrm{pH}$ : studies in isolated beating hearts and myocytes loaded with the indicator Indo 1. J. Physiol. (London). 480(2):203-215.

20. Steadman, B. W., K. B. Moore, K. W. Spitzer, and J. H. B. Bridge. 1988. A video system for measuring motion in contracting heart cells. IEEE (Inst. Electr. Electron. Eng.) Trans. Biomed. Eng. 35:264-272.

21. Cheung, J. Y., D. L. Tillotson, R. V. Yelamarty, and R. C. Scaduto Jr. 1989. Cytosolic free calcium concentration in individual cardiac myocytes in primary culture. Am. J. Physiol. 256:C1120-C1130.

22. Borzak, S., R. A. Kelly, B. K. Kramer, Y. Matoba, J. D. Marsh, and M. Reers. 1990. In situ calibration of fura-2 and BCECF fluorescence in adult rat ventricular myocytes. Am. J. Physiol. 259:H973-H981.

23. Arkhammer, P., T. Nilsson, and P. O. Berggren. 1990. Glucose-stimulated efflux of indo-1 from pancreatic beta-cells is reduced by probenecid. FEBS ( $\mathrm{Fed}$. Eur. Biochem. Soc.) Letts. 273:182-184.

24. DiVirgilio, F., T. H. Steinberg, J. A. Swanson, and S. C. Silverstein. 1988 Fura-2 secretion and sequestration in macrophages. A blocker of organic anion transport reveals that these processes occur via a membrane transport system for organic anions. J. Immunol. 140:915-920.

25. Pirolo, J. S., and D. G. Allen. 1986. Assessment of techniques for preventing glycolysis in cardiac muscle. Cardiovasc. Res. 20:837-844.

26. Quaife, R. A., O. Kohmoto, and W. H. Barry. 1991. Mechanisms of reoxygenation injury in cultured ventricular myocytes. Circulation. 83:566-577.

27. Gwathmey, J. K., R. J. Hajjar, and R. J. Solaro. 1991. Contractile deactivation and uncoupling of crossbridges. Effects of 2,3-butanedione monoxime on mammalian myocardium. Circ. Res. 69:1280-1292.

28. Adams H. 1963. Adenosine 5'-triphosphate determination with phosphoglycerate kinase. In Methods of Enzymatic Analysis. H. V. Bergmeyer, editor. Academic Press, NY. 539-543.

29. Altschuld, R. A., A. Weiss, F. A. Kruger, and A. M. Weissler. 1969. Anaerobic performance and metabolism of the hyperthyroid heart. J. Clin. Invest. 48:1905-1913.

30. Schunkert, H., B. Jackson, S.-S. Tang, F. J. Schoen, J. F. M. Smits, C. S. Apstein, and B. H. Lorell. 1993. Distribution and functional significance of cardiac angiotensin converting enzyme in hypertrophied rat hearts. Circulation. 87:1328 1339.

31. Feldman, A. M., E. O. Weinberg, P. E. Ray, and B. H. Lorell. 1993. Selective changes in cardiac gene expression during compensated hypertrophy and the transition to cardiac decompensation in rats with chronic aortic banding. Circ. Res. 73:184-192.

32. Schwartz, K., Y. LeCarpentier, J. L. Martin, A. M. Lompre, J. J. Mercardier, and B. Swynghedauw. 1981. Myosin isoenzymic distribution correlates with speed of myocardial contraction. J. Mol. Cell. Cardiol. 13:1071-1075.

33. Feldman, A. M., P. E. Ray, C. M. Silan, J. A. Mercer, W. Minobe, and M. R. Bristow. 1991. Selective gene expression in failing human heart. Quantification of steady state levels of messenger RNA in endomyocardial biopsies using the polymerase chain reaction. Circulation. 83:1866-1872.

34. Gwathmey, J. K., and J. P. Morgan. 1985. Altered calcium handling in experimental pressure-overload hypertrophy in the ferret. Circ. Res. 57:836-843.

35. Spurgeon, H. A., M. D. Stern, G. Baartz, S. Raffaeli, R. G. Hansford, A. Talo, E. G. Lakatta, and M. C. Capogrossi. 1990. Simultaneous measurement of $\mathrm{Ca}^{2+}$, contraction, and potential in cardiac myocytes. Am. J. Physiol. 258:H574H586.

36. Berlin, J. R., M. B. Cannell, and W. J. Lederer. 1989. Cellular origins of the transient inward current in cardiac myocytes. Role of fluctuations and waves of elevated intracellular calcium. Circ. Res. 65:115-126.

37. Sollott, S. J., B. D. Ziman, and E. G. Lakatta. 1992. Novel technique to load indo-1 free acid into single adult cardiac myocytes to assess cytosolic $\mathrm{Ca}^{2+}$. Am. J. Physiol. 262:H1941-H1949.

38. Hoerter, J. A., C. Lauer, G. Vassort, and M. Gueron. 1988. Sustained function of normoxic hearts depleted in ATP and phosphocreatine: a ${ }^{31} \mathrm{P}-\mathrm{NMR}$ study. Am. J. Physiol. 255:C192-C201.

39. He, M. X., M. W. Gorman, G. D. Romig, R. A. Meyer, and H. V. J. Sparks. 1991. Adenosine formation and energy status during hypoperfusion and 2-deoxyglucose infusion. Am. J. Physiol. 260:H917-H926.

40. Kentish, J. C. 1986. The effects of inorganic phosphate and creatine phosphate on force production in skinned muscles from rat ventricle. J. Clin. Invest. 370:584-604.

41. Marban, E., and H. Kusuoka. 1987. Maximal $\mathrm{Ca}^{2+}$-activated force and myofilament $\mathrm{Ca}^{2+}$ sensitivity in intact mammalian hearts. Differential effects on inorganic phosphate and hydrogen ions. J. Gen. Physiol. 90:609-623.

42. Nichols, C. G., and W. J. Lederer. 1990. The role of ATP in energy- 
deprivation contractures in unloaded rat ventricular myocytes. Can. J. Physiol. Pharmacol. 68:183-194.

43. Ingwall, J. S. 1994. Is failing myocardium energy-starved? The role of the creatine kinase system. Heart $F$. 10:128-136.

44. Weinberg, E. O., I. Reis, J. S. Ingwall, and B. H. Lorell. 1994. Creatine kinase activity in compensated hypertrophy and failure. Circulation Suppl. 90:1 159. (Abstr.)

45. Bittl, J. A., and J. S. Ingwall. 1987. Intracellular high-energy phosphate transfer in normal and hypertrophied myocardium. Circulation. 75:96-101.

46. Taegtmeyer, H., and M. L. Overturf. 1988. Effects of moderate hypertension on cardiac function and metabolism in the rabbit. Hypertension. 11:416426.

47. Sivitz, W. I., D. D. Lund, B. Yorek, M. Grover-McKay, and P. G. Schmid. 1992. Pretranslational regulation of two cardiac glucose transporters in rats exposed to hypobaric hypoxia. Am. J. Physiol. 263:E562-E569.

48. Lopaschuk, G. D., Spafford, M. A., and D. R. Marsh. 1991. Glycolysis is the predominant source of myocardial ATP production immediately after birth Am. J. Physiol. 261:H1698-H1705.

49. Doorey, A. J., and W. H. Barry. 1983. The effects of inhibition of oxidative phosphorylation and glycolysis on contractility and high-energy phosphate content in cultured chick heart cells. Circ. Res. 53:192-201.

50. Winegrad, S., G. McClellan, A. Weisberg, S. Weindling, and L. E. Lin 1988. Variable calcium sensitivity of the mammalian cardiac contractile system. In Diastolic Relaxation of the Heart. W. Grossman and B. H. Lorell. MartinusNijhoff Publishing, Boston. 27-32.

51. Gao, W. D., P. I. Backx, M. Azan-Backx, and E. Marban. 1994. Myofilament $\mathrm{Ca}^{2+}$ sensitivity in intact versus skinned rat ventricular muscle. Circ. Res. 74:408-415.

52. Hibberd, M. G., J. A. Dantzig, D. R. Trentham, and Y. E. Goldman. 1985. Phosphate release and force generation in skeletal muscle fibers. Science (Wash. DC). 228:1317-1319.

53. Hoar, P. E., C. W. Mahoney, and G. L. Kerrick. 1987. MgADP increases maximum tension and $\mathrm{Ca}^{2+}$ sensitivity in skinned rabbit soleus fibers. Pflüger Arch. Eur. J. Physiol. 410:30-36.

54. Bremel, R. D., and A. Weber. 1972. Cooperation within actin filament in vertebrate skeletal muscle. Nature New Biol. 238:97-101.

55. Yamashita, H., M. Sata, S. Sugiura, S. Momomura, T. Serizawa, and M. lizuka. 1994. ADP inhibits the sliding velocity of fluorescent actin filaments on cardiac and skeletal myosins. Circ. Res. 74:1027-1033. 